Uusitalo P., Olivieri H., Seppänen O., Pikas E., and Peltokorpi A. (2017). "Review of Lean Design Management: Processes, Methods and Technologies" In LC3 2017 Volume II - Proceedings of the 25th Annual Conference of the International Group for Lean Construction (IGLC), Walsh, K., Sacks, R., Brilakis, I. (eds.), Heraklion, Greece, pp. 571-578. DOI: https://doi.org/10.24928/2017/0224

\title{
REVIEW OF LEAN DESIGN MANAGEMENT: PROCESSES, METHODS AND TECHNOLOGIES
}

\author{
Petteri Uusitalo ${ }^{1}$, Hylton Olivieri ${ }^{2}$, Olli Seppänen ${ }^{3}$, Ergo Pikas ${ }^{4}$ and Antti \\ Peltokorpi $^{5}$
}

\begin{abstract}
Lean Design Management (LDM) has been used by lean practitioners to manage the design process in construction. Several methods, processes and tools have been successfully implemented, such as the Last Planner System (LPS), Target Value Design (TVD), Set-Based Design and Design Structure Matrix. However, despite the increased use of LDM, many attributes are still applied in an isolated manner. Thus, there is a lack of an integrated framework which takes into account possible combinations of LDM methods, processes, and technologies used by designers and construction companies.

The aim of this paper is to analyse design management attributes based on a literature review, case studies and interviews with practitioners, in three countries (Finland, Norway and United States), which have previously reported advanced lean design management implementations. Three new attributes were identified based on the case studies and interviews: Location-Based Design Management, Level of Detail and Real-time cost estimation. The completed list of attributes was presented to three Finnish contractors, and each selected a different combination of tools for their project which will be used as case studies in future research. Future research will test new combinations of LDM tools and evaluate their interactions and benefits to the project teams.
\end{abstract}

Keywords: Lean Design Management, Lean Construction, Last Planner System, Virtual Design and Construction, Collaboration

\section{INTRODUCTION}

Design in construction has been explored by lean practitioners through the concept of Lean Design Management (LDM, Koskela et al. 1997), transforming customer needs into engineering specifications and outputs (Ballard and Koskela 1998). Regardless of project delivery method, many methods, processes and tools have been used to support LDM, such as Last Planner System (LPS, Ballard 2000), Target Value Design (TVD, Ballard 2006), Set-Based Design (Lee et al. 2012) and Design Structure Matrix (Huovila et al.

1 Doctoral Student, Aalto University, Department of Civil Engineering; Rakentajanaukio 4 A, P.O. Box 12100, 00076 Aalto, petteri.uusitalo@aalto.fi

2 Postdoctoral Researcher, Aalto University, Department of Civil Engineering, hylton.olivieri@,aalto.fi

3 Professor of Practice, Aalto University, Department of Civil Engineering, olli.seppanen@aalto.fi

4 Doctoral Student, Civil Engineering Dept., Aalto University, Tallinn University of Technology ergo.pikas@,aalto.fi

5 Assistant Professor, Aalto University, Department of Civil Engineering, antti.peltokorpi@aalto.fi 
1997). In addition, the use of Virtual Design in Construction (VDC) in association with LDM is an emerging area and is being developed rapidly by both academia and construction industry (Khanzode et al. 2008, Bølviken et al. 2010, Franco and Picchi 2016). Lean and Building Information Modelling (BIM) are known to have interconnections and significant synergies between them, but both are still independent from another and can be used separately (Sacks et al. 2010). However, despite the increased use of LDM, many processes are still applied in an isolated manner. Thus, there is a lack of solutions which include the most relevant processes, methods and tools in an integrated framework.

To promote the understanding of the integration of design and production, this research examines design management concepts, tools and methods focusing on the detailed engineering and document production phase. The goal of this paper is to analyse design management attributes based on a literature review and an interview study of practitioners in countries which have previously reported advanced lean design management implementations. Our hypothesis is that to fully control the reciprocal link between design and production, companies are implementing only a part of the lean design management toolkit and so far, no company has mastered them all in an integrated system.

\section{BACKGROUND}

LDM has been explored in literature mainly through different social processes, methods and technologies. In this chapter, we briefly summarize each based on literature.

LPS has been studied a lot by the lean community, reducing waste and process variability and getting stakeholders more committed to the project (Koskela et al. 1997, Bolviken et al. 2010, Fosse and Ballard 2016, Franco and Picchi 2016). Collaborative Planning in Design is an adaptation of Last Planner System to design management which has been developed by the Norwegian construction company, Veidekke. The method focuses on the collaborative design production and decision-making processes (Bølviken et al. 2010). Thus, in addition to technical planning and coordination, LPS and Collaborative Planning in Design introduce the need for social processes management.

Related to social processes, there are several approaches have been developed to improve collaboration between stakeholders. Big Room is an on-site space that enables designers, builders and owner to work together and solve issues that need close participation of everyone. The main aim is to improve team collaboration trough higher integration (Khanzode et al. 2008). Co-location brings all the team members together to the same physical space. It is best used by having team members from different organizations who have interdependencies within the product and between the tasks, to work close to each other in the site office in clusters (Thompson and Ozbek 2012). Big Room meetings are held only periodically but co-location is an essential part of team members' every-day activities. Continuous co-location is closely related to Big Room, but it enhances the project team information flow by reducing the time wasted while searching up-to-date information. Integrated Concurrent Engineering is a form of extreme collaboration and simultaneous engineering, where usually highly motivated team members solve interdependent design issues in a good and productive environment with a pre-planned agenda and clear objectives (Ballard and Koskela 1998, Kunz and Fischer 2009, Knotten and Svalestuen 2014). 
Several methods and tools have been developed to support Lean Design Management. TVD is a model for collaboration where the designing process starts from customer's business case and the cost estimation and the design is driven by the value which the owner has defined (Ballard 2006). Target is to maximize the produced value by paying attention to cost, time and other limitations. Set-Based Design is a method which can support TVD, where issues are solved by having several possible design alternatives in play. Different alternatives are narrowed out while adding detail. Finally, at the last responsible moment, the best design solution or alternative is chosen (Lee et al. 2012). Another concept which can support TVD is Choosing by Advantages, which is a method where advantages of design alternatives are considered and used to make comparisons to choose the best design alternative (Munthe-Kaas et al. 2015).

Design Structure Matrix is a tool where tasks are defined, their relation and information need from other tasks, and from that information an optimal task sequence is indicated in the matrix (Huovila et al. 1997). Dialogue Matrix is a good tool to structure design meetings. The matrix is based on questions to other designers and answers are pulled from other team members (Bølviken et al. 2010). A3 Report is a tool, originally developed by Toyota Motor Corporation, which is used for problem-solving and it streamlines the design process (Sobek and Jimmerson 2004).

In terms of technologies, the key technology for LDM is VDC, which is a more advanced form of BIM. VDC is more than just coordination of Mechanical, Electrical and Plumbing (MEP) systems. The whole building and its technical systems are parametrically modelled in three-dimensional environment which enables the model to be used for different analysing and production planning needs, four-dimensional scheduling being a good example (Khanzode et al. 2008). BIM is closely linked to lean construction (Sacks et al. 2010).

\section{METHOD}

First, a literature review was carried out, aiming to investigate the concepts related to LDM. Second, a series of small international case studies (mini-cases) and face-to-face company-level interviews were done, aiming to find out the main concepts, systems and tools used by the companies. A standard list of 25 questions was prepared and 12 semistructured interviews were done in three countries (Finland, Norway and United States/California). Norway and California were selected because several case studies had been reported in lean construction literature (Ballard 2008, Khanzode et al. 2008, Kunz and Fischer 2009, Knotten and Svalestuen 2014, Fosse and Ballard 2016). Finland was selected because Finnish contractors have formed a Vision 2030 consortium which explores LDM as a topic in their research program. The case study and interview findings were categorized in three groups of attributes: 1) Social processes, 2) Methods, and 3) Tools and technologies. Finally, the combined list of attributes was presented to three Finnish companies and future action research was proposed, based on case studies implementing different combinations of LDM attributes.

\section{Results}

\subsection{Concepts, systems and tools used by companies}

Veidekke previously documented use of Collaborative Planning in Design (Bølviken et al. 2010), a system based on the LPS concepts, applying the same techniques used in 
production to the design process. The main elements of Collaborative Planning in Design are: 1) The start-up session, aiming at a common understanding of the project scope through the perspectives of the designers and stakeholders; 2) The scheduling system, which starts with a master schedule and then applies the phase scheduling process, detailing the activities through the look ahead and weekly schedules; 3) Constraints removal, using tools such as Dialogue Matrix to improve communication among designers and project teams, and; 4) Meetings structure, where standard topics are used to guide the biweekly meetings. The interviews at Veidekke helped the research team understand Collaborative Planning in Design better but new design management attributes were not found.

Ramboll is an engineering, design and consultancy company founded in Denmark in 1945. Aiming to overcome the typical challenges in design management, such as the coordination of designers and the management of resources, combined with LPS the company uses Scrum in their design management (Cobb 2011). Underlined by pull principle, it is an incremental and iterative design management methodology, often used together with Kanban boards. It is a workflow management tool to enable pull-based design production, limit the work-in-process and prevent overdesign. For that, activities are prioritized in order of relevance, and then managed through the backlog for later follow-up, or inserted in a sprint screen, where project teams can follow the status of every activity. Scrum was originally developed to be used in agile software development projects. In construction projects, it is used as a designer's tool to improve predictability and to control risks (Owen and Koskela 2006). Backlog is a tool to prioritize design tasks and short sprints are used to effectively to finish those tasks.

Skanska Norway is the largest construction company in Norway. Skanska has implemented a CIFE certified VDC (Kunz and Fischer 2009) approach for design, planning and execution of building projects. LPS, Big Room and Integrated Concurrent Engineering sessions are also used in Skanska's projects. Like Veidekke in Norway, Skanska is using Dialogue Matrix in their design meetings and metrics are used to follow progress.

Skanska USA has been in the United States market since 1971 and it is the $3^{\text {rd }}$ largest building contractor by revenue. Skanska is a founding member of Lean Construction Institute and it uses Lean approaches in their projects such as Big Room, LPS and TVD. VDC is also part of Skanska's project delivery. For managing complex design prioritizing, Design Structure Matrix is used with the software called ADePT (Choo et al. 2008).

Suffolk Construction, founded in 1982, is based in Boston, Massachusetts. In Suffolk's 24 story high-rise building project at 340 Fremont in San Francisco, California, VDC is used extensively with all the major trades and their multiple drawings and models are coordinated into one federated model. That model is also used for cost estimation purposes. Real-time cost estimation in construction is a difficult task that has been difficult to resolve (Lai et al. 2006). BIM-based real-time cost estimation is based on the link between model components and cost line items. This is an effective way of giving almost instant cost feedback of the design changes.

Suffolk uses a milestone driven pull plan to manage design. Differently from other reviewed case studies, they explicitly manage the Level of Detail of models based on milestone requirements. Different milestones are set for the permitting requirements, the coordination requirements, setting the Guaranteed Maximum Price, procurement requirements, construction start and long lead-time items. With each milestone, the level 
of detail rises for each system. Suffolk used an excel-based tool to manage different designers and their outputs. Leite et al. (2011) defined Level of Detail as a process where building information models and the complexity of their components progress from the lowest level of conceptual representation to the highest level of detail based on component's use, for example for fabrication or installation needs. Suffolk is helping the designers focus on the deliverables of current design phase by giving them a requirements list so they can pull information and commitments from other project parties. For design, pull plan meetings were typically held once per milestone.

Sutter Health's Hospital project at Van Ness and Geary Campus is an Integrated Lean Project Delivery with Sutter Health, SmithGroupJJR architects and a partnership of Herrero Builders and The Boldt Company. The companies are all working together under an Integrated Form of Agreement which includes an integrated team of equal partners. All the stakeholders were brought on early to develop the project using TVD (Hamzeh et al. 2009). VDC is highly used in the project and some of the modellers doing the detailing are former installers. This arrangement lowers the risk of possible constructability issues. BIM is also used to plan production and visualize the design. Teams are co-located in clusters and each discipline related to the cluster (for example designers and subcontractors related to MEP rough-in phase) are in the same physical location with regularly scheduled meetings. Detailed design is done in these clusters and is managed by location. LPS is used to manage design hand-offs. LPS pull scheduling is implemented so that milestones are formed by every location and a location-based production schedule is driving the design so that modelling and document production is using the same locations as construction and they are sequenced in the order of construction. This method to manage detailed design driven by a location-based schedule can be called LocationBased Design Management. To shorten response time, the Owner has provided five or six people full time right in the project office to shorten the design decision lead time. A3 reports and culture of learning and continuous improvement are used in the project.

All the attributes identified from the literature review, interviews and mini-cases are listed in Table 1. Combining interview and mini-case data with literature review, we formed an idea of what are the current best practices globally. Each company or minicase has an " $X$ " in the cell if they are applying the method or tool in their current projects. Circled X's are those new attributes, that are less documented and were discovered from the mini-cases or interviews.

\subsection{Proposed combined model}

To select a combined model (which includes methods, processes and tools) for testing in future research and case projects, a workshop was held with Finnish construction and design companies participating in the Vision 2030 consortium. They selected the combination of tools and methods for testing in case study projects presented in Table 1.

In addition to Company One's (Case 1 in Table 1) current attributes in use, they chose Design Structure Matrix as a method for prioritizing the design tasks and to reveal those tasks that require Integrated Concurrent Engineering sessions to complete them. SetBased Design was chosen because the Company One needed a tool to help manage design options for example on parking garage decks. To support that method, Choosing by Advantages was also chosen in the toolbox. Dialogue Matrix was chosen with the idea that it would replace Company One's current design meeting structures with the goal of diminishing or eliminating design meeting minutes and memos. Company Two (Case 2 in Table 1) chose to test Big Room and study it to see if it could be applied virtually 
because of the long distances between their project parties in their normal project. They selected Level of Detail as a method to be accompanied with Real-time cost estimation, for example pricing the change orders from the owner.

The difference separating Company Three (Case 3 in Table 1) from the two other companies, is the fact that Company Three is construction management consultant and not a General Contractor like Companies One and Two. Company Three chose Virtual Big Room to their toolbox to test on the next project. TVD is chosen because of the normal role of Company Three in construction projects. They are typically hired by the owner and TVD is natural choice in the toolbox which supports the company's collaborative approach to projects. Both Companies Two and Three wanted to research more about VDC. Their goal is to develop a standard network of design dependencies for their projects.

Table 1: Attributes of Lean Design Management.

\begin{tabular}{|c|c|c|c|c|c|c|c|c|c|}
\hline Attributes of Lean Design Management & 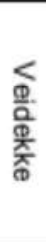 & 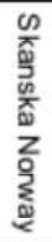 & 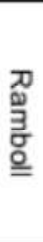 & 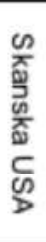 & 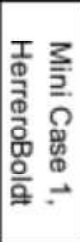 & 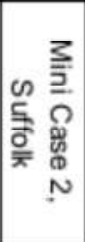 & 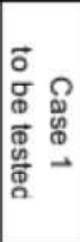 & 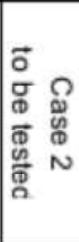 & 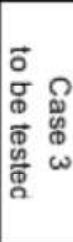 \\
\hline \multicolumn{10}{|l|}{ 1. SOCIAL PROCESS } \\
\hline LPS & $\mathrm{x}$ & $x$ & $\mathrm{x}$ & $x$ & $x$ & $x$ & $x$ & $\mathrm{x}$ & $x$ \\
\hline Big Room & $\mathrm{x}$ & $x$ & & $\mathrm{x}$ & $\mathrm{x}$ & $x$ & $x$ & $x$ & $\mathrm{x}$ \\
\hline Co-location & & & & & $x$ & & & & \\
\hline Integrated Concurrent Engineering (ICE) & $\mathrm{x}$ & $x$ & & & & & $x$ & & \\
\hline Collaborative Planning in Design (CPD) & $\mathrm{x}$ & & & & & & & & \\
\hline \multicolumn{10}{|l|}{ 2. METHODS } \\
\hline Level of Detail (LOD) & & & & & & (x) & & $x$ & $x$ \\
\hline \multicolumn{10}{|l|}{ Location-Based Design Management (LBDM) } \\
\hline Target Value Design (TVD) & & & & $\mathrm{x}$ & $x$ & & & & $x$ \\
\hline Set-Based Design (SBD) & & & $\mathrm{x}$ & $\mathrm{x}$ & & & $x$ & & \\
\hline Choosing by Advantages (CBA) & & & & & & & $x$ & & \\
\hline Real-time cost estimation & & & & & & (x) & & $\mathrm{x}$ & \\
\hline \multicolumn{10}{|l|}{ 3. TOOLS / TECHNOLOGIES } \\
\hline Virtual Design and Construction (VDC) & $\mathrm{x}$ & $x$ & $\mathrm{x}$ & $\mathrm{x}$ & $x$ & $x$ & $x$ & $x$ & $x$ \\
\hline Design Structure Matrix (DSM) & & & & $x$ & & & $x$ & & \\
\hline Dialogue Matrix (DM) & $\mathrm{x}$ & $x$ & & & & & $x$ & & \\
\hline A3 Report & & & & & $x$ & & & & \\
\hline Scrum & & & $x$ & & & & & & \\
\hline
\end{tabular}

\section{Conclusions}

The contribution of this research is to review different social processes, tools and methods based on the literature and evaluate their use within different companies by using interviews and mini-cases. In addition to the LDM tools reported in literature, we found three new ones in the interviews. All the social processes, tools and technologies form a toolbox of design management. Some of the tools, for example LPS and BIM/VDC, have been studied more than others, but different combinations and how they generate positive 
interactions and outcomes have not received the attention they deserve. Projects are unique and design is a complex art of producing engineering outputs of customers' needs. Finding the optimal balance between people, process and technology, is hard because different companies use different attributes, as we found from the interviews and minicases. Thus, in our future empirical research we attempt to test the proposed models and combinations to find out how they affect the project teams and design management results. Performance measurement metrics to evaluate the results of case studies also need to be developed.

\section{REFERENCES}

Ballard, G. and Koskela, L. (1998), "On the Agenda of Design Management Research." Proceedings of the 6th Annual Conference of the International Group for Lean Construction. Guarujá, Brazil.

Ballard, H. G. (2000), “The Last Planner System of Production Control." Ph.D. Diss., Civil Engineering, The University of Birmingham, Birmingham, 192 pp.

Ballard, G. (2006), "Rethinking Project Definition in Terms of Target Costing." Proceedings of the 14th Annual Conference of the International Group for Lean Construction. Santiago, Chile

Ballard, G. (2008), “The lean project delivery system: An update”. Lean Construction Journal, 2008: 1-19.

Bølviken, T., Gullbrekken, B. \& Nyseth, K. (2010), "Collaborative Design Management." Proceedings of the 18th Annual Conference of the International Group for Lean Construction. Haifa, Israel.

Choo, H. J., Hammond, J., Tommelein, I. D., Austin, S. A., and Ballard, G. (2004). "DePlan: a tool for integrated design management." Automation in Construction, 13(3), 313-326.

Cobb, C.G. (2011), "Making Sense of Agile Project Management: Balancing Control and Agility." John Wiley \& Sons, New Jersey.

Demir, S.T., and Theis, P. (2016), "Agile Design Management - The Application of Scrum in the Design Phase of Construction Projects." Proceedings of 24th Annual Conference of the International Group for Lean Construction. Boston, MA, USA.

Fosse, R. and Ballard, G. (2016), "Lean Design Management in Practice with the Last Planner System." Proceedings of the 24th Annual Conference of the International Group for Lean Construction. Boston, MA, USA, 20-22 Jul 2016.

Franco, J.V. and Picchi, F.A. (2016), "Lean Design in Building Projects: Guiding Principles and Exploratory Collection of Good Practices." Proceedings of the 24th Annual Conference of the International Group for Lean Construction. Boston, MA, USA.

Hamzeh, F.R., Ballard, G. and Tommelein, I.D. (2009), "Is the Last Planner System Applicable to Design?" A Case Study Proceedings of the 17th Annual Conference of the International Group for Lean Construction. Taipei, Taiwan

Huovila, P., Koskela, L., Lautanala, M., Pietiläinen, K., and Tanhuanpää, V. (1997), “Use of the design structure matrix in construction." Lean Construction, 417-425.

Khanzode, A., Fischer, M., and Reed, D. (2008), "Benefits and lessons learned of implementing building virtual design and construction (VDC) technologies for coordination of mechanical, electrical, and plumbing (MEP) systems on a large 
healthcare project." Journal of Information Technology in Construction [1874-4753] v:2008 vol:13 s:324

Knotten, V. and Svalestuen, F. (2014), "Implementing Virtual Design and Construction (VDC) in Veidekke - Using Simple Metrics to Improve the Design Management Process." Proceedings of 22th Annual Conference of the International Group for Lean Construction, Oslo, Norway.

Koskela, L., Ballard, G., and Tanhuanpää, V. P. (1997), “Towards lean design management." Proceedings of the 5th Annual Conference of the International Group for Lean Construction. Gold Coast Australia.

Kunz, J., and Fischer, M. (2009), "Virtual design and construction: themes, case studies and implementation suggestions. " Center for Integrated Facility Engineering (CIFE), Working Paper \#097 Version 14; January 2012 Stanford University.

Lai, C. C., and Lee, W. L. (2006), "A WICE approach to real-time construction cost estimation." Automation in construction, 15(1), 12-19.

Lee, S., Bae, J., and Cho, Y. S., 2012, "Efficiency analysis of set-based design with structural building information modelling (S-BIM) on high-rise building structure." Automation in Construction, Elsevier, vol.23, p.20-32.

Leite, F., Akcamete, A., Akinci, B., Atasoy, G., and Kiziltas, S. (2011), "Analysis of modeling effort and impact of different levels of detail in building information models." Automation in Construction, 20(5), 601-609.

Munthe-Kaas, T.S., Hjelmbrekke, H., Lohne, J. and Lædre, O. (2015), "Lean Design Versus Traditional Design Approach" Proceedings of the 23rd Annual Conference of the International Group for Lean Construction. Perth, Australia.

Owen, R. L., and Koskela, L. (2006), “Agile construction project management." In 6th International Postgraduate Research Conference in the Built and Human Environment (Vol. 6, No. 7).

Sacks, R., Koskela, L., Dave, B. A., and Owen, R. (2010), "Interaction of lean and building information modeling in construction." Journal of construction engineering and management, 136(9), 968-980.

Sobek II, D.K. and Jimmerson, C. (2004), "A3 reports: tool for process improvement." Proceedings of the Annual Conference of the Institute of Industrial Engineers.

Thompson, R. D., and Ozbek, M. E. (2012), "Utilization of a Co-location Office in conjunction with Integrated Project Delivery." Proceedings of the 48th ASC Annual International Conference. 